\title{
INSPIRAÇÃO DIVINA E TÉCNICA NARRATIVA NA ILÍADA
}

\begin{abstract}
Barbara Graziosi*
RESUMO: Este artigo estabelece um diálogo entre abordagens modernas da Ilíada e concepções antigas do poema como divinamente inspirado. Ele começa com uma análise da invocação à Musa e passa a perguntar de qual perspectiva a estória é contada, usando a noção de cronotopo de Bakthin. Ele conclui mostrando que algumas estórias antigas sobre o poeta Homero refletem uma apreciação sensível da voz do poeta dentro da Ilíada.
\end{abstract}

PALAVRAS-CHAVE: Inspiração divina; narratologia; cronotopo; tempo; espaço; catálogo; écfrase; símiles; Ilíada; biografias de Homero.

\section{DIVINE INSPIRATION AND NARRATIVE TECHNIQUE IN THE ILIAD}

\begin{abstract}
This article sets up a dialogue between modern approaches to the Iliad and ancient conceptions of the poem as divinely inspired. It starts with an analysis of the invocation to the Muse and proceeds to ask from what perspective the story is told, using Bakhtin's notion of the chronotope. It concludes by showing that some ancient stories about the poet Homer reflect a sensitive appreciation of the poet's voice within the Iliad.
\end{abstract}

KEYWORDS: Divine inspiration; narratology; chronotope; time; space; catalogue; ekphrasis; similes; Iliad; biographies of Homer.

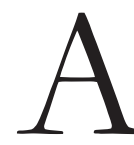

Ilíada começa com uma ordem: "Canta, deusa, a ira de Aquiles". Como todos os endereçamentos à segunda pessoa, esta abertura estabelece uma relação específica entre o falante e o destinatário. $\mathrm{O}$ poeta pede à deusa para cantar e ela evidentemente atende a seu pedido, porque o que se segue é precisamente uma canção sobre a ira de Aquiles. Após a invocação de abertura, o poeta e a Musa cantam em uníssono: já não é possível
* Professor in the Department of Classics and Ancient History - Durham University. 
distinguir a voz do poeta da voz da deusa. ${ }^{1}$ Em momentos de uma tensão excepcional, no entanto, o poeta parece desprender-se: ele faz uma pausa, reflete sobre as dificuldades que enfrenta, e declara que elas são grandes demais para um mortal comum. Um exemplo famoso desta separação momentânea entre o poeta e a Musa acontece um pouco antes do Catálogo das Naus, servindo-lhe como proêmio (II, 484-93):

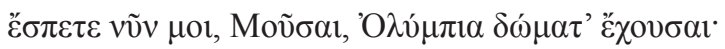

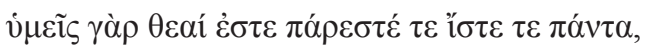

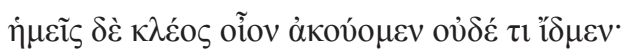

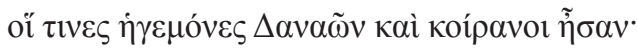

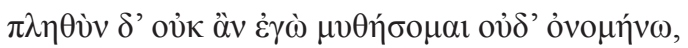

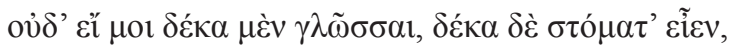

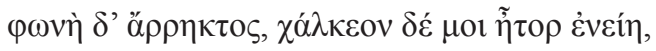

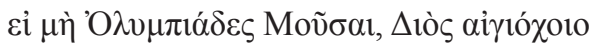

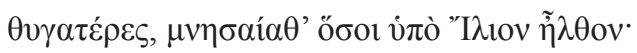

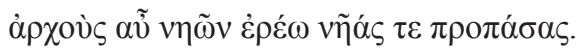

Dizei-me agora, vós Musas que tendes vossas casas no Olimpo,pois vós sois deusas, estais presentes, e sabeis todas as coisas, mas nós ouvimos apenas o rumor, e nada sabemos quem eram os chefes e senhores dos Dânaos.

Eu não poderia descrever a multidão deles, nem nomeá-los, nem se eu tivesse dez línguas e dez bocas, nem se eu tivesse uma voz inquebrantável e um coração de bronze em mim, a não ser que as Musas do Olimpo, filhas de Zeus porta-égide, lembrassem todos aqueles que vieram sob Ílion; agora eu direi os chefes dos navios, e as naus em sua totalidade.

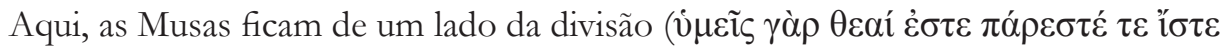
$\tau \varepsilon \pi \alpha ́ v \tau \alpha$, "vós sois deusas, estais presentes, e sabeis todas as coisas"), enquanto o poeta e

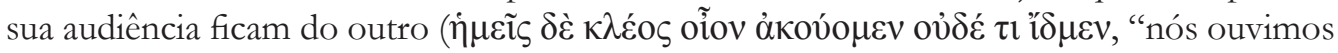
apenas o rumor, e nada sabemos"). O que o poeta constrói, portanto, é uma hierarquia simples: visão, conhecimento e divindade ("vós") ficam acima da audição, da ignorância e da mortalidade ("nós"). O notável nesta passagem é que o poeta momentaneamente coloca-se entre a sua audiência de mortais comuns. Ele também afirma estar condenado a ouvir, mesmo que o que se segue, após o verso 493, seja o mais impressionante feito de canto. Parece, assim, que, depois de colocar alguma distância entre ele e as Musas, o poeta prossegue para demonstrar a sua proximidade a elas ao enunciar o Catálogo das Naus. O Catálogo acaba por ser não apenas um feito de performance, mas, como argumento abaixo, de visualização.

\footnotetext{
${ }^{1}$ Cf. Clay, 2011, p. 15.
} 
Há outros momentos, na Ilíada, nos quais o poeta chama a atenção para as dificuldades que enfrenta. Em XII, 175-6, por exemplo, ele duvida de sua capacidade de descrever o múltiplo ataque troiano à muralha aqueia:

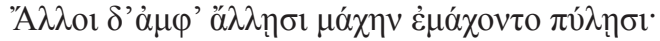

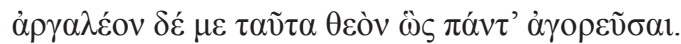

Eles todos combatiam, cada um em um portão diferente, mas seria difícil para mim, como se eu fosse um deus, descrever todas essas coisas.

Como no início do Catálogo das Naus, também aqui o poeta momentaneamente nos arranca para fora da narrativa e comenta suas próprias limitações humanas ("seria difícil para mim descrever todas essas coisas"). Naturalmente, as dificuldades do poeta só servem para realçar suas realizações, já que, depois de reconhecer que não é um deus, ele prossegue para nos oferecer uma visão divina, literalmente. Adiante, os versos XII, 179-80 descrevem a reação dos deuses à batalha e, depois disso, o poeta se lança em uma descrição excepcionalmente complexa de como a luta se desenrola, simultaneamente, em várias frentes diferentes. Como aponta Strauss Clay, na narrativa complexa que se segue, o poeta parece sempre saber (ou ver) a localização exata de seus personagens: "se sua atenção se desloca para outro lugar por um tempo e depois retorna, ele os encontra novamente onde estavam, seja no mesmo lugar ou naquele para onde estavam indo. [...] Ao longo de milhares de versos, encontramos surpreendentemente pouca confusão. Seu controle notável sobre as atividades de seus personagens se torna mais evidente quando a narrativa divide os combates em várias arenas." Strauss Clay dificilmente pode disfarçar sua admiração pelo dom de visualização do poeta, e por sua capacidade de descrever a ação simultânea: "Como ele faz isso?", pergunta ela. ${ }^{3}$ Essa sensação de surpresa é reivindicada pelo próprio poeta, pois, em XII, 175-6, ele sugere que a tarefa que executa é divina.

Do ponto de vista do poeta, então, há uma diferença entre o seu próprio eu mortal e as Musas, "que são deusas, estão presentes, e sabem todas as coisas" (II, 485). Do ponto de vista da audiência, no entanto, o poeta descreve os eventos em Troia como se ele próprio fosse um deus: ele também parece estar presente e saber todas as coisas. Uma passagem da Odisseia oferece alguns comentários úteis sobre as capacidades e limitações do poeta - e sobre sua relação com a Musa. No canto VIII, o cantor Demódoco executa três canções na corte feácia: a primeira diz respeito a uma briga entre Odisseu e Aquiles (VIII, 62-92); a segunda se passa no Olimpo e descreve um caso de amor adúltero entre Ares e Afrodite (VIII, 256-369); e a terceira comemora a queda de Troia e o estratagema de Odisseu do cavalo de Troia (VIII, 469-520). Demódoco é cego: ele não sabe que Odisseu, o personagem principal de suas próprias canções, está ali mesmo, na frente dele. É Odisseu que se reconhece na primeira canção de Demódoco: ele puxa para cima seu manto roxo, cobre a cabeça e chora

\footnotetext{
${ }^{2}$ Clay, 2011, p. 52.

${ }^{3}$ Clay, 2011, p. 52.
} 
(VIII, 83-92). Mais tarde, antes da terceira canção de Demódoco, ele elogia o cantor com estas palavras (VIII, 487-491):

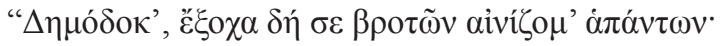

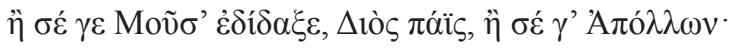

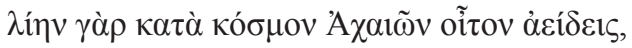
ö $\sigma \sigma^{\prime}$ '

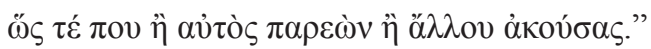
"Demódoco, bem acima de todos os mortais, eu te louvo;
ou a Musa, filha de Zeus, te ensinou, ou Apolo.
Você canta o destino dos Aqueus precisa e ordenadamente;
o que fizeram e sofreram e todas as dores que suportaram,
como se você mesmo estivesse lá, ou alguém tivesse te contado”.

Depois de prestar o seu elogio a Demódoco, Odisseu pede ao bardo para cantar a queda de Troia e o estratagema do Cavalo. E é depois desta performance que ele finalmente revela sua identidade: nos cantos IX-XII, Odisseu assume o lugar de Demódoco e conta aos feácios o que aconteceu depois da queda de Troia. É-nos dito que eles acreditam no que conta Odisseu, porque ele soa exatamente como um cantor (XI, 363-8); mas há, de fato, algumas diferenças entre a performance de Odisseu e as canções de Demódoco. Em primeiro lugar, como Jørgensen apontou em um artigo famoso, Odisseu não tem a capacidade de descrever os deuses. ${ }^{4}$ Em segundo, Odisseu oferece um relato de uma real testemunha ocular (ou assim ele o diz), enquanto Demódoco nunca poderia fazer isso, porque ele é cego. O conhecimento que o cantor tem de Troia não se baseia em experiência de primeira mão; é um dom da Musa (VIII, 63-4):

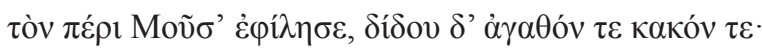

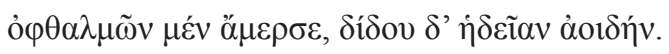

A Musa o amava sobremaneira, e deu-lhe um presente bom e um mau: ela privou-o de seus olhos, mas deu-lhe um suave canto.

A permuta delineada na Odisseia é simples: Demódoco goza de uma relação estreita com as Musas, mas permanece visualmente separado de sua audiência. Ele não vê Odisseu na Feácia, quando ele está bem na frente dele; no entanto, ele pode ver suas ações passadas em Troia. Audiências antigas pensavam que Demódoco foi um personagem autobiográfico e, como argumento abaixo, elas especificamente conectaram a cegueira de Homero à sua capacidade de ver seus próprios personagens. ${ }^{5}$

\footnotetext{
${ }^{4}$ Jørgensen, 1904.

${ }^{5}$ Para Demódoco como um personagem autobiográfico, ver ademais Graziosi, 2002, p. 138-42. Para a cegueira do poeta e sua capacidade de ver Aquiles, no esplendor cegante e desconcertante de sua armadura divina, ver abaixo, referência cruzada.
} 
Assim como Demódoco, o poeta da Ilíada descreve, com clareza de testemunha ocular, pessoas, eventos e coisas remotas. ${ }^{6}$ Vários estudiosos têm argumentado que a memória, na Ilíada, não é conceituada como a capacidade de recordar um lugar ou evento que pertence ao passado, mas sim um estado específico de consciência ou, como eu a chamaria, uma "presença de espírito". Ford traduz mnemosýnē como "atenção plena" em vez de memória; Bakker argumenta que "a memória em Homero (...) é muito mais uma questão do presente; ela encena, torna presente, no sentido mais literal". ' Minha contribuição se baseia no trabalho destes e de outros estudiosos, e indaga, mais especificamente, como o poeta transmite uma sensação de sua presença em Troia, enquanto nos lembra, ao mesmo tempo, que o mundo dos heróis é remoto e, de fato, totalmente inacessível aos mortais comuns. Assim como as Musas, que estão presentes em Troia e simultaneamente presentes no momento da performance, assim também o poeta realiza uma transação complexa. Além do mais, ele chama a atenção para essa transação, ao sugerir que a inspiração divina concerne, acima de tudo, à capacidade de fundir espaço e tempo e "estar presente". A memória torna-se, então, um ato de presença - um encontro.

Em um ensaio seminal publicado em 1937, Bakhtin insistiu na interdependência de espaço e tempo na formação da narrativa, e apresentou a categoria do "cronotopo" como um meio de analisar ambas as coordenadas, a espacial e a temporal, de um texto, sem privilegiar qualquer uma das duas. ${ }^{8}$ A Iliada, "poema de Troia", nos apresenta o cronotopo perfeito: para o poeta e sua audiência, é um espaço carregado com os movimentos da história, ou, dito de outra forma, uma cidade onde a história pode ser visualizada. No que se segue, considero o relacionamento do poeta com este cronotopo, para melhor situar a sua voz. Começo com uma discussão do tempo, e, em seguida, investigo a manipulação do espaço pelo poeta embora minha distinção nítida de tempo e espaço falhe tanto na teoria como na prática: considerações espaciais infiltram-se em minha discussão do tempo e vice-versa. Em última análise, considero as Musas responsáveis por isso (em vez de Bakhtin). Como já veio à tona, as Musas fundem, ambos, tempo e espaço em um único ato de presença. Elas cantam em uníssono com o poeta, e estão simultaneamente presentes em Troia. O poeta da mesma forma se move entre o aqui-e-agora da sua performance e o aqui-e-agora da ação em Troia. Esses dois modos de presença são difíceis de conciliar, porque o mundo dos heróis não só é passado, mas também está em outro lugar. O que pretendo investigar é como o poeta se posiciona tanto em relação a sua audiência quanto a seu assunto - como ele consegue "estar

\footnotetext{
${ }^{6}$ A muralha aqueia, por exemplo, desaparece sem deixar vestígios: para nós a única maneira de vê-la é ouvir o poeta, que descreve tanto a sua construção quanto a sua eventual destruição: Ilíada XII, 17-33. Aristóteles conhecidamente toma a muralha aqueia como um exemplo das ficções do poeta: "o que o poeta faz ele pode destruir", sobre o quê ver ademais Porter, 2011 - mas, mesmo em uma leitura mais ingênua da Ilíada (fr. 162 Rose), a muralha lembra-nos que o poeta pode fazer-nos ver o que não está mais lá.

${ }^{7}$ Ford, 1992, p. 53; Bakker, 2005, p. 141.

${ }^{8}$ Bakhtin, 1981, p. 84-258; para uma boa discussão, ver Todorov, 1984.
} 
presente", enquanto chama a atenção para as grandes distâncias (espaciais e temporais) que percorre a fim de transmitir a sua estória.

Há uma maneira óbvia com a qual o poeta coloca seu assunto no passado: ele usa os tempos passados - aoristo e imperfeito - para descrever a ação em Troia. Esta é uma característica tão óbvia da narrativa homérica que muitas vezes escapa à atenção, mesmo que muitos outros épicos tradicionais recorram ao presente, a fim de transmitir a imediaticidade da ação. ${ }^{9}$ Uma maneira de explicar isso é simplesmente dizer que, no momento em que a Ilíada foi composta, o presente histórico ainda não tinha sido "inventado". Mas o que me interessa não é o que estava disponível para o(s) compositor(es) real(is) da Ilíada, mas sim como as audiências antigas ouviram a voz do poeta. Mesmo depois de autores antigos começarem a usar o presente histórico, poetas gregos compondo no molde homérico abstiveram-se de fazê-lo, presumivelmente porque o presente não soava homérico a eles. ${ }^{10}$

É possível que os tempos passados da Ilíada tenham atingido as audiências clássica, helenística e romana com mais força do que as arcaicas, não só porque a ausência do presente histórico, eventualmente, se tornou perceptível, mas também porque o aumento uma sílaba extra que caracteriza os tempos passados no grego clássico, mas aparece apenas esporadicamente em Homero - pode ter perdido sua força dêitica original. Bakker argumenta que, na épica homérica, o aumento apontava para a encenação da história em performance. ${ }^{11}$ Esta é uma sugestão interessante e, talvez, melhore a nossa compreensão de algumas passagens da Ilíada - mas continua a ser difícil avaliar se, e, em caso afirmativo, até que período, o aumento realmente atingiu audiências antigas como se ajudando a encenar a estória no presente. Talvez os rapsodos tenham enfatizado a força dêitica do aumento muito tempo depois de ele ter se tornado um recurso padrão do grego, mas não é fácil ver como eles conseguiram fazer isso. Em qualquer caso, mesmo que o aumento pudesse ter tido força dêitica, os aoristos e imperfeitos homéricos ainda ancoravam a narrativa firmemente no passado.

As audiências gregas antigas eram bem conscientes de que aqueles que lutaram em Troia viveram muito antes do seu tempo. Para elas, os heróis eram uma raça totalmente diferente: mais fortes, mais próximos dos deuses e também - de certa forma - mais primitivos do que os mortais comuns. ${ }^{12}$ Comunidades gregas antigas cultuavam os heróis, sacrificavam em seus túmulos, e pediam sua ajuda e proteção. ${ }^{13}$ Embora uma analogia com os Santos dificilmente seja apropriada, os heróis foram, de fato, considerados uma categoria intermediária de seres, equilibrada entre os deuses e os mortais comuns. Vários indícios sugerem que os gregos estavam interessados no preciso status ontológico e até mesmo biológico dos heróis. Por exemplo, o fascínio antigo com a sua dieta - que agora parece

\footnotetext{
${ }^{9}$ Devo este ponto a Clay, 2011, p. 19. Sobre o presente na épica medieval francesa, ver, por exemplo, Fleischman, 1990, p. 273-4.

${ }^{10}$ Sobre Apolônio, ver Clay, 2011, p. 18, nota 11. Sobre Ênio e Virgílio, que importaram o presente histórico para dentro da épica, ver Rossi, 2004, p. 125-49.

${ }^{11}$ Bakker, 2005, p. 114-35.

${ }^{12}$ Aqui resumo grosseiramente Graziosi e Haubold, 2005.

${ }^{13}$ Burkert, 1985, p. 203-8; Ekroth, 2002.
} 
um tópico muito desconcertante da antiga crítica de Homero - tem suas raízes em uma simples pergunta: até que ponto os heróis eram ou não eram como seres humanos comuns. O poeta da Ilíada oferece, ocasionalmente, um comentário explícito sobre as diferenças entre os protagonistas de sua estória e os "homens tais como são hoje em dia". ${ }^{14}$ Nos símiles, ele faz também comparações entre o mundo heróico e aspectos da vida como ela é "agora" (isto é, na Grécia arcaica). ${ }^{15}$ Em uma passagem famosa, ele até mesmo descreve aqueles que morreram em Troia como "uma raça de homens semideuses", $\dot{\eta} \mu 1 \theta \dot{\varepsilon} \omega v \gamma \varepsilon \dot{\varepsilon} v o \zeta$ $\alpha \delta \rho \tilde{\omega} v$, chamando, assim, a atenção para a grande distância entre o seu próprio tempo e a idade dos heróis. ${ }^{16}$ Tais reflexões explícitas sobre o hiato temporal entre heróis e mortais comuns são, no entanto, raras na Ilíada. Na maior parte do tempo, o poeta coloca em primeiro plano a perspectiva dos deuses e heróis, em vez daquela de suas audiências. Ele dificilmente se refere ao culto heroico, por exemplo. O ponto central da narrativa não é enfatizar as honras póstumas concedidas aos heróis, mas sim dramatizar o quão difícil eles próprios acham a perspectiva da morte. ${ }^{17}$ Para esta finalidade, o poeta emprega muitos dispositivos diferentes, todos os quais sugerem a sua proximidade com os heróis e a sua distância das audiências humanas comuns, "como elas são hoje em dia".

A impressão é que, embora a narrativa seja colocada firme e indiscutivelmente no passado, o poeta experimenta o passado como presente. As apóstrofes diretas que pontuam a narrativa são um bom exemplo disso. O poeta nunca aborda explicitamente a sua audiência a fim de lisonjear, explicar as coisas, ou pedir sua atenção, por exemplo - mas ele fala com as Musas, Apolo e alguns de seus próprios personagens. ${ }^{18}$ Estas apóstrofes são tão surpreendentes, que leitores antigos e modernos se envolveram em intermináveis especulações sobre elas. ${ }^{19}$ Muitos argumentaram que o poeta sente um carinho especial pelos personagens aos quais ele se dirige, ou, de algum modo, percebe quão centrais eles são para sua narrativa: isso pode ser verdade para Menelau e Pátroclo, mas o caso de Melanipo em XV, 582-3 parece bastante diferente. Não há nenhuma razão para supor uma preocupação permanente com este personagem menor. O poeta aborda Melanipo imediatamente depois que ele foi morto, e assinala que Heitor defendeu seu corpo (XV, 582-4):

\footnotetext{
${ }^{14}$ Ilíada V, 302-4; XII, 445-9; XX, 285-7; cf. XII, 381-3.

${ }^{15}$ Cf. Edwards, 1991, p. 35: "[Os símiles] nos dão uma visão do mundo (...) que existia na própria época do poeta e muito depois dele."

${ }^{16}$ Ilíada XII, 23. Significativamente, a expressão aparece na mesma passagem em que o poeta afirma que a muralha aqueia desapareceu sem deixar vestígios. Sobre os "homens semideuses" e seu desaparecimento, ver Clay, 2003, p. 161-74.

${ }^{17}$ Ver ademais Graziosi e Haubold, 2005, p. 100-1.

${ }^{18} \mathrm{O}$ mais próximo que o poeta alguma vez chega a falar com sua audiência é pelo seu uso de expressões gerais como "você poderia pensar", "você diria" (IV, 429; XV, 697; XVII, 366).

${ }_{19}$ As passagens estão recolhidas e discutidas em Block, 1982; Yamagata, 1989, e Richardson, 1990, p. 170-4. Para uma breve, mas útil, discussão, ver Clay, 2011, p. 20.
} 


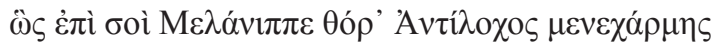

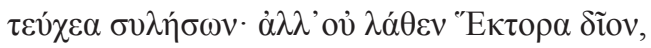

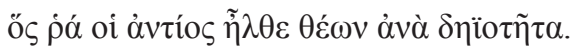

assim Antíloco, firme na batalha, lançou-se sobre ti, Melanipo, visando arrancar tua armadura. Mas o glorioso Heitor o viu, e veio passando rapidamente pelo combate para encontrá-lo.
\end{abstract}

Ao invés de dirigir estes versos para a sua audiência, o poeta os endereça a Melanipo, que está morto - e de fato morto há muito tempo. A impressão, é claro, é que o poeta está logo ali em Troia, quando Antíloco lança-se sobre o cadáver de Melanipo e Heitor intervém. $\mathrm{Na}$ verdade, o poeta delonga-se por trás de sua própria narrativa: ele ainda fala com Melanipo, momentos depois que ele foi morto. Tal é o modo como ele está envolvido.

O desprendimento do poeta da sua audiência, e sua capacidade de estar lá com seus personagens, pode ajudar a explicar uma outra característica intrigante da narrativa homérica. Em um estudo influente de 1899-1901, Theodor Zielinski argumentou que a narrativa homérica sempre se move para a frente: como resultado, o poeta representa ações simultâneas como sequenciais. As primeiras reações à "lei de Zielinski" a tomaram como prova do estado primitivo da mente de Homero, que era supostamente incapaz de compreender as complexidades da simultaneidade..$^{20}$ Discussões mais recentes insistem que Zielinski estava errado, e que o poeta da Ilíada, na realidade, representa a ação simultânea - por vários meios diferentes. ${ }^{21}$ Ainda assim, o fato de que sua chamada "lei" tem estado na agenda homérica por bem mais de um século sugere-me que deve haver algo nela a ser considerado. Como já veio à tona, o poeta descreve eventos como se estivesse lá - presente, como as Musas. Referências explícitas à simultaneidade dissipariam a impressão de que ele é uma testemunha direta: para dizer que um evento estava ocorrendo, enquanto outra coisa estava acontecendo em outro lugar, o poeta teria de ficar atrás de ambos os eventos, mesmo que brevemente, e se juntar à sua audiência para ver a ação à distância, ou em retrospectiva. Isso, em geral, ele não faz: muitas vezes ele se move de uma visão para outra - dando pouca orientação à sua audiência sobre a transição. Como resultado, não é claro se o poeta está descrevendo eventos simultâneos ou consecutivos, se mudou de lugar, mas ficou dentro do fluxo do tempo, ou se também voltou no tempo. Em seu novo e instigante livro, Strauss Clay mapeia o campo de batalha e como os guerreiros nele se movem, nos cantos XII-XVII. Ela oferece uma visão surpreendentemente coerente, também expressa por uma simulação on-line..$^{22} \mathrm{Eu}$

\footnotetext{
${ }^{20}$ Ver, por exemplo, Fränkel, 1955.

${ }^{21}$ Ver, por exemplo, de Jong, 2007, p. 30-1; Scodel, 2008; e Clay, 2011.

${ }^{22}$ Clay (2011), com o site http://www.homerstrojantheater.org/. O processamento visual do poema por Clay não está, evidentemente, além da controvérsia. Tenho inteira certeza, por exemplo, de que ela localiza mal a figueira.
} 
tenho problemas com alguns aspectos de sua reconstrução, ${ }^{23}$ mas ela certamente mostra que o poeta repetidamente volta no tempo. Ainda assim, permanece a questão sobre se as audiências e os leitores são encorajados a tomar conhecimento desta volta no tempo, ou se a ênfase permanece no aqui e agora da narrativa (no entanto, ela pode dizer respeito a "aquis e agoras" anteriores e posteriores). A minha opinião é que a simulação de Strauss Clay ajuda muito a explicar como o(s) compositor(es) e, de fato, os rapsodos dominavam a narrativa complexa da batalha dos cantos XII a XVII. A audiência, no entanto, não precisava estar a par da ação exatamente da mesma maneira. Assim, o poeta não faz nenhum esforço especial para garantir que os ouvintes coordenem o que está acontecendo em diferentes seções do campo de batalha: não há nenhum lembrete didático explícito, por exemplo, de que enquanto Deífobo e Meríones estão engajados na esquerda, Teucro luta no centro (XIII, 156; 170). Um rapsodo (ou um leitor profissional como Strauss Clay) pode resolver isso - depois de anos de estudo; mas, para a maioria das audiências, é suficiente perceber que o poeta sabe o que está acontecendo em todos os lugares e em todos os momentos. ${ }^{24}$

Pode haver razões mais profundas pelas quais o poeta deixa de enfatizar as diferenças entre a ação simultânea e a consecutiva. De sua perspectiva divina, pode ser que tais diferenças sejam triviais. As Musas têm conhecimento completo do que foi, é e será; e o poeta pode semelhantemente examinar o passado, o presente e o futuro de seus personagens em uma única visualização. O tempo oportuno (timing) é por vezes explicitamente apresentado como uma preocupação mortal. Quando Andrômaca chora por Heitor antes que ele esteja realmente morto, seu comportamento é um escândalo, um mau presságio: ele ainda está vivo, apesar de tudo, e, enquanto ele vive, ela deveria - para usar o slogan britânico em tempo de guerra - "manter-se calma e prosseguir". ${ }^{25}$ Mas, quando Tétis lamenta por Aquiles antes de sua hora ter realmente chegado, isso dificilmente é algo controverso: Tétis é uma deusa, sabe com certeza que seu filho é de-vida-breve e, em seu próprio reino submarino à parte, ela já chora por ele. ${ }^{26}$ Reiteradamente, o poeta mostra que seus personagens sabem muito pouco sobre o passado, o presente e (especialmente) o futuro, ao passo que ele tem um controle completo e divino sobre tudo em todos os momentos. De muitas maneiras, Helena é a personagem que mais se aproxima de partilhar a perspectiva do poeta sobre a guerra de Troia. A primeira vez que a encontramos na Ilíada, ela está tecendo um grande manto que descreve "as lutas dos Troianos domadores-de-cavalo e dos Aqueus vestidos-de-bronze" (III, 125): ela pode pintar a grande imagem, assim como o poeta. Um pouco depois, Príamo pede a ela para identificar os guerreiros Aqueus mais proeminentes na planície: ela o cumpre,

\footnotetext{
${ }^{23}$ Tenho igualmente considerações específicas (por exemplo, sobre a localização da figueira, que deve estar mais próxima das muralhas de Troia do que Clay [2011] sugere) e reservas gerais sobre a alegada clareza das coordenadas espaciais no poema: ver abaixo a nota 24.

${ }^{24}$ Apesar de suas alegações de estar mudando o foco da composição para a recepção (2011, p. 14-15), parece-me que Clay (2011, p. 104) ainda vê as coisas da perspectiva dos compositores/performers, em vez da das audiências.

${ }^{25}$ Ilíada, VI, 485-93, com Graziosi e Haubold, 2010, ad loc.

${ }^{26}$ Iliada, XXIV, 83-6.
} 
realizando assim um catálogo dos Aqueus que complementa o anterior catálogo das naus do próprio poeta. E, no entanto, as limitações humanas de Helena em breve tornam-se evidentes: ela se pergunta por que não pode ver seus dois irmãos entre os Aqueus (III, 23442), e é precisamente neste ponto que o poeta faz sua revelação: eles estão mortos há muito tempo, na verdade morreram em Esparta antes mesmo da partida da expedição para Troia (III, 243-4). Ele conhece o passado muito melhor do que Helena, que - embora seja uma filha de Zeus como as Musas - ainda tem óbvias limitações mortais.

Há muitas outras ocasiões em que o poeta chama a atenção para a ignorância de seus próprios personagens. Bem conhecidamente, ele descreve Andrômaca preparando um banho para Heitor, enquanto na muralha os Troianos já estão lamentando sua morte (XXII, 440-6):

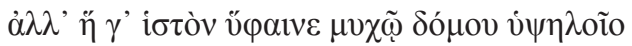

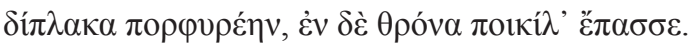

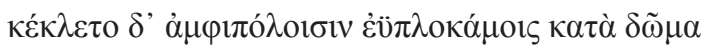

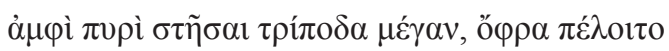

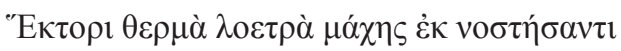

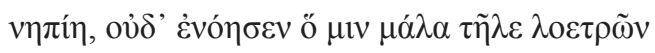

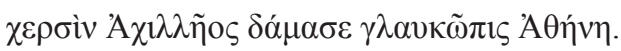

Ela estava em seu tear, na parte mais interna da casa alta, tecendo um duplo manto vermelho, e nele trabalhando

Ela chamou através da casa suas servas de-lindos-cabelos

[um padrão de flores.

para porem um grande tripé sobre o fogo, para que Heitor pudesse ter um banho quente quando voltasse dos combates -

pobre inocente que ela era, não sabia que Atena de-olhos-glaucos

o tinha abatido pelas mãos de Aquiles, bem longe dos banhos.

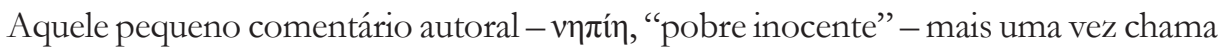
a atenção para a distância entre o conhecimento do poeta e a incerteza de seus personagens. Andrômaca se comporta como uma mulher, quando na verdade ela já é uma viúva.

Mesmo Aquiles, que normalmente é bastante consciente de suas circunstâncias, se recusa a contemplar os detalhes de sua morte iminente: quando Heitor, momentos antes de expirar o seu último suspiro, lhe diz - com uma clareza profética - exatamente onde e como ele também irá em breve ser morto, Aquiles se recusa a considerar essa informação. Ele responde secamente que vai morrer "quando for para ser", enquanto Heitor deve morrer "agora" (XXII, 365). Isso é tudo o que importa para Aquiles e para todos nós, mortais comuns: se morremos "agora" ou "quando for para ser". A perspectiva do poeta não poderia ser mais diferente: ele conhece, com igual certeza, o passado, o presente e o futuro de todos os seus personagens. Ele pode examinar todo o seu destino em uma única visualização. 
Em uma passagem famosa de sua Poética, Aristóteles elogia a Ilíada porque o poeta não tenta nos contar toda a estória da Guerra de Troia. Sua trama diz respeito apenas a um punhado de dias mais para o fim da guerra e pode ser facilmente examinada em um único ato de visualização (1459a30-4):

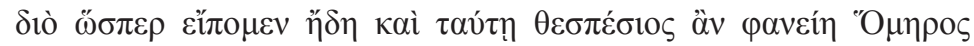

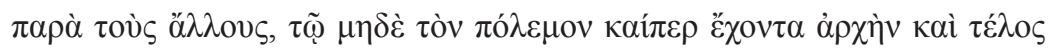

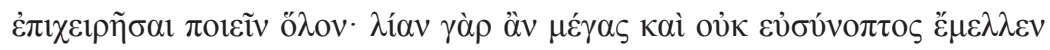

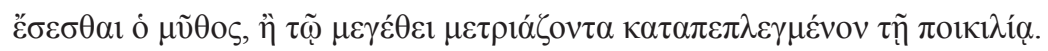

Assim como dissemos antes, Homero pareceria falar de uma maneira divina em comparação com os outros, na medida em que ele não tenta fazer da guerra um todo, mesmo que ela tenha tido um começo e um fim. Pois o enredo de outra forma teria sido demasiado grande e não facilmente visto de uma só vez, ou, se reduzido em comprimento, cuidadosamente bem tecido com detalhes.

Em seu recente livro Space and Time in Ancient Greek Narrative, Purves, com razão, chama a atenção para o adjetivo que Aristóteles usa para caracterizar o enredo da Ilíada:

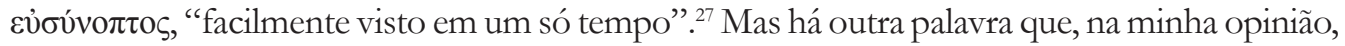
merece igual atenção: $\theta \varepsilon \sigma \pi \varepsilon ́ \sigma 10 \varsigma$, "que fala divinamente". Até mesmo o técnico Aristóteles admite que há algo divino quanto à percepção do tempo, ou da trama, por Homero em um único ato de visualização.

Uma maneira de investigar a relação do poeta com seu assunto é perguntar, bem simplesmente, de que ponto de vista ele conta sua estória ou, mais concretamente, de onde ele vê a ação. No início do canto XIII, o poeta descreve uma impressionante sequência de eventos. Zeus está sentado sobre o Monte Ida, observando a ação abaixo na planície de Troia, mas, em algum momento, se distrai e começa a olhar para mais longe, para o nordeste de Troia (XIII, 1-9):

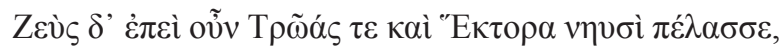

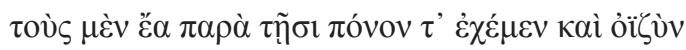

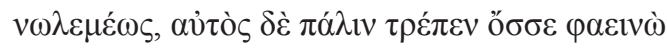

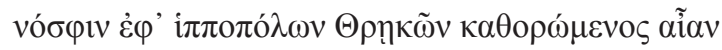

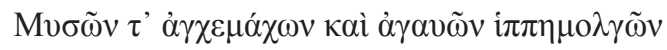

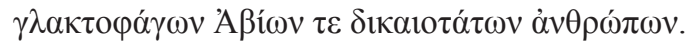

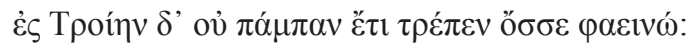

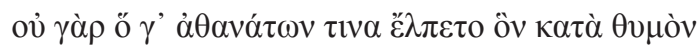

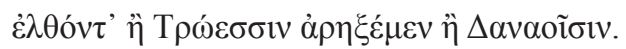

\footnotetext{
${ }^{27}$ Purves, 2010, p. 24-64.
} 
Agora, quando Zeus trouxe os Troianos e Heitor aos navios, deixou os combatentes ao lado deles para suportar fadiga e miséria sem cessar, enquanto ele próprio desviou seus olhos brilhantes, olhando longe para a terra dos Trácios criadores-de-cavalos, e dos Mísios, lutadores corpo-a-corpo, e dos esplêndidos Hipemolgos, bebedores de leite de éguas, e dos Ábios, os mais retos dos homens. Mas para Troia ele não desviou em nada seus olhos brilhantes, uma vez que não esperava em seu coração que qualquer imortal viria para ajudar nem os Troianos nem os Dânaos.

Posêidon imediatamente percebe a distração de Zeus, a partir de seu próprio posto de observação, uma montanha na ilha de Samotrácia, a noroeste de Troia (XIII, 12). Ele salta para baixo da montanha e entra no mar, arma-se em seu palácio submarino em Eges, e depois vai ajudar os Aqueus no campo de batalha. Enquanto isso, Hera estava observando toda a sequência de eventos a partir do topo do Monte Olimpo: a fim de ajudar a causa aqueia, ela decide fazer uma visita a Zeus, seduzi-lo, distraí-lo ainda mais e, assim, deixar Posêidon continuar seu bom trabalho embaixo na planície de Troia. A imagem é clara: Posêidon e Zeus estavam observando a guerra sentados nos cimos de montanhas opostas, enquanto Hera estava os observando e ao campo de batalha a partir do Monte Olimpo. A questão é: de onde o poeta está vendo toda esta cena? Ele deve desfrutar de algum ponto de vista panorâmico igualmente elevado - embora não nos seja dito exatamente onde ele está em relação aos outros três observadores divinos pousados nos cimos das montanhas.

No decorrer da narrativa, temos indicações mais específicas sobre o ponto de vista privilegiado do poeta, especificamente em relação à ação no campo de batalha. Quando o poeta utiliza os marcadores dêiticos "esquerda" e "direita", ele sempre olha para o campo de batalha da mesma perspectiva: mantém as suas costas para o mar, de frente para a planície de Troia e para a cidade de Ílion, além dela. O litoral curvo, com suas naus aqueias encalhadas, se organiza diante dele "como um teatro", como um erudito antigo (provavelmente Aristarco) observou. ${ }^{28}$ Quando o poeta fala com sua própria voz, "esquerda" e "direita" sempre indicam que ele está vendo a ação a partir dessa posição. Embora alguns estudiosos insistam no tratamento imparcial de Troianos e Aqueus pelo poeta, ele está literalmente do lado dos Aqueus. ${ }^{29}$ Sua posição ancora a narrativa e torna possível para ele, e na verdade para nós, obter uma imagem de como a ação se desenrola no campo de batalha. O poeta, no entanto, não é obrigado a ver a ação do seu privilegiado ponto de vista padrão, pairando em algum lugar acima do mar e encarando Troia. Ele pode aproximar o foco e descrever, por exemplo, como a lança de Polipetes atravessa a testa de Dâmaso, fazendo, por dentro, pasta do cérebro (XII, 181-7). Leitores contemporâneos costumam comentar as qualidades cinematográficas da Ilíada; mas, para audiências antigas, a capacidade do poeta de aproximar

\footnotetext{
${ }^{28}$ Homeri Scholia (Ariston.) ad XIV, 30-6.

${ }^{29}$ Ver Cuillandre, 1944, p. 41, que insiste justamente no privilegiado ponto de vista helênico do poeta; para uma excelente discussão de "esquerda" e "direita" na Ilíada, ver agora Clay, 2011, especialmente p. 45-9.
} 
e distanciar o foco da ação era divina. ${ }^{30}$ Somente um deus poderia ver as coisas de cima, ou observar a luta de perto, sem medo da morte. O próprio poeta observa isso em IV, 539-44, quando invoca a perspectiva de um observador objetivo e invulnerável no campo de batalha:

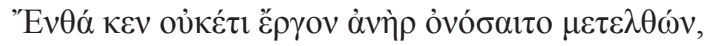

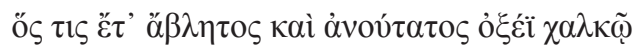

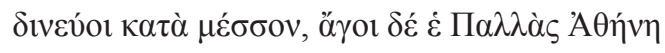

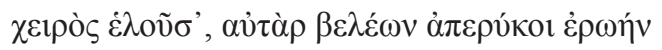

Então não mais poderia um homem, chegando, criticar seus trabalhos de alguém que, ainda ileso e não golpeado pelo bronze agudo, [guerra se movesse no meio deles, pois Palas Atena o levaria, tomando sua mão e afastando as lanças que se aproximavam.

Comentadores antigos pensavam que este observador hipotético era o poeta, mas também consideravam que a passagem oferecia uma descrição apropriada da sua audiência. ${ }^{31}$ Como o comentarista bizantino Eustácio coloca, "o homem que ouve o poeta seria um tal espectador, alguém que não participa dos males da guerra, mas aprecia a bela visão da narrativa de guerra em sua mente, participando, portanto, sem perigo, da batalha."${ }^{{ }^{32}}$

Bem como aproxima o foco, o poeta traz a audiência diretamente para a ação de outras maneiras também. Uma técnica que recebeu surpreendentemente pouca atenção é o que eu chamaria de "voz sobreposta". Às vezes, quando uma determinada ação se desenrola, o poeta preenche o tempo, oferecendo algumas informações de fundo. Assim, por exemplo, em VI, 393, Andrômaca vê Heitor da muralha e começa a correr em direção a ele. O poeta, enquanto isso, conta-nos alguns fatos básicos sobre suas origens, família e casamento, até que, de repente, em 399, ele terminou, e Andrômaca pára diante de Heitor. O tempo da narrativa coincide, assim, com o tempo da performance: Andrômaca corre, enquanto o poeta nos fala sobre ela. ${ }^{33}$ Exatamente a mesma técnica é empregada um pouco antes no canto VI, quando Heitor procura Andrômaca em casa. Ele entra em casa e vai procurá-la - enquanto o poeta nos diz que ela está, na verdade, na muralha (VI, 371-5). ${ }^{34} \mathrm{O}$ efeito desta técnica da voz sobreposta é, como sempre, o de reforçar um sentimento de "presença" do poeta: ele fala enquanto observa o que seus personagens estão fazendo.

\footnotetext{
${ }^{30}$ Sobre Homero e o cinema, ver Winkler, 2007; mais especificamente sobre a "aproximação do foco" (“zooming”), ver de Jong e Nünlist, 2004.

31 Scholia bT ad 4.541 e Eustácio logo abaixo. Para uma excelente discussão moderna, ver Mirto, 1997, p. 925.

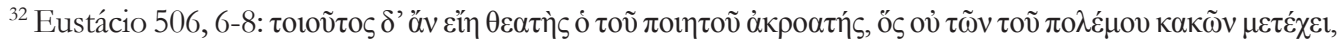

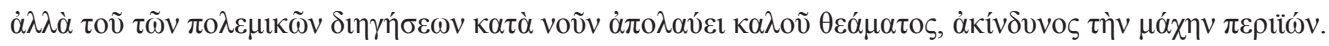

${ }^{33}$ Ver ademais Graziosi e Haubold, 2010, p. 44 e ad 395-8.

${ }^{34}$ Ver Graziosi e Haubold, 2010, ad 369-91.
} 
A focalização, uma técnica que tem recebido muito mais atenção do que a da voz sobreposta, em estudos recentes, muitas vezes tem um efeito similar. O poeta, por vezes, parece estar bem próximo de seus personagens, ver as coisas de sua perspectiva, e até mesmo adotar seu tom e linguagem. Em VI, 401, por exemplo, quando Heitor olha para o seu filho pequeno Astíanax, o poeta adota o tom de um pai amoroso, enchendo o menino de palavras de carinho. Só um pouco mais tarde, no entanto, quando é Astíanax que olha para seu pai, é que o poeta compartilha a perspectiva confusa e atemorizada do menino (VI, 468-70). Embora o poeta tenha grandes poderes de empatia, ele pode, assim, mudar as perspectivas rápida e facilmente. Como isso teria acontecido na performance é uma questão interessante. $\mathrm{Na}$ descrição memorável e antipática de Platão, o rapsodo Íon afirma ser capaz de sentir todos os tipos de emoções diferentes durante sua performance. ${ }^{35}$ Assim, podemos imaginá-lo semelhante a Heitor - e, de repente, mudando o papel e se tornando o Astíanax apavorado, que grita ao ver o capacete de seu pai. Comentadores antigos, com razão, observaram a vivacidade, غ̇vópyeı $\alpha$, do encontro entre Heitor, Andrômaca e Astíanax, e rapsodos devem ter explorado as possibilidades dramáticas e até mesmo cômicas na performance. ${ }^{36}$ Através da encenação de diferentes perspectivas, eles trariam a audiência diretamente para dentro da cena.

Símiles homéricos também exigem mudanças bruscas na localização e perspectiva. Podemos supor que o poeta, ao comparar alguma coisa com outra diferente, se posiciona temporariamente atrás de ambas as ações, a fim de vê-las à vontade, a partir da perspectiva de seu público - mas isso muitas vezes não é assim. Símiles frequentemente incluem, ou implicam, um observador interno: este observador descentraliza de imediato a narrativa, o que sugere que o poeta não está simplesmente se posicionando atrás desta, a fim de se juntar à sua audiência e fazer comparações à vontade - ele, de repente, foi completamente para outro lugar. Em XXIII, 759-6, por exemplo, o poeta nos diz que Odisseu corre logo atrás de Ájax na corrida a pé, quase alcançando-o, e, então, nos oferece este símile:

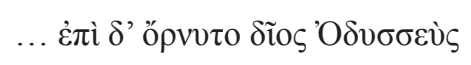

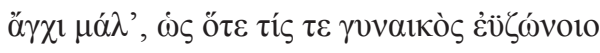

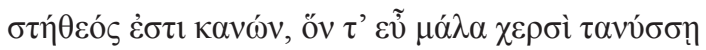

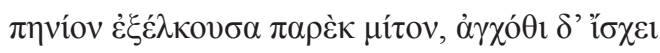

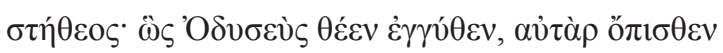

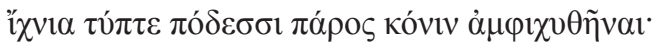

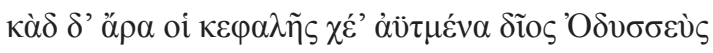

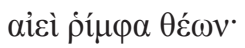

... depois dele chegou o glorioso Odisseu, correndo muito perto, tão perto como a haste de tecelagem

[de uma mulher bem-cinturada

\footnotetext{
${ }^{35}$ Ver Platão, Íon 535c-e, discutido abaixo.

${ }^{36}$ Ver Scholia bT ad 6.467, em Graziosi e Haubold, 2010, p. 23-4.
} 
está contra seu peito, enquanto ela habilmente, com as mãos, a pressiona forte, puxando o carretel ao longo da urdidura, e segurando-o perto de seu peito; tão perto estava Odisseu enquanto corria atrás de Ájax, seus pés pisando em suas pegadas antes que a poeira pudesse se fixar nelas; e, enquanto o glorioso Odisseu mantinha sua rápida corrida, sua respiração se mantinha pairando em torno da cabeça Ájax.

Há uma sensação palpável, neste símile, de que a mulher está sendo observada enquanto trabalha. Enquanto ela tece sua tela, com movimentos regulares e repetidos, podemos imaginar alguém olhando para ela (um marido? uma criança? um parente?) e percebendo o quão perto ela pressiona a haste de tecelagem na direção de seus seios. Da mesma forma, na visão do poeta, Odisseu pressiona Ájax mais de perto na corrida a pé. Ao enunciar o símile, o poeta muda repentinamente de localidade e de perspectiva, sem nos dar muita orientação sobre a transição: em um minuto estamos desfrutando de um momento de intimidade doméstica, no seguinte estamos de volta à pista de corrida, sentindo a respiração de Odisseu em nossas orelhas.

É precisamente um símile que oferece o melhor comentário interno sobre as mudanças repentinas de perspectiva e localidade do poeta. Hera, nos é dito, viaja na velocidade do pensamento (XV,80-4):

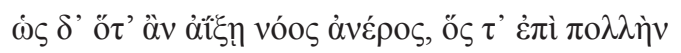

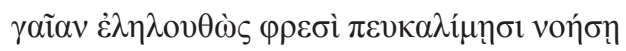

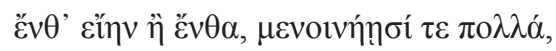

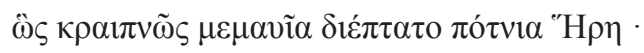

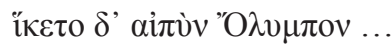

Tão rapidamente quanto a mente astuta de um homem que viajou por muitas terras dispara entre os muitos pensamentos que ele mantém, dizendo para si mesmo "eu gostaria de estar neste ou naquele lugar", tão rapidamente a Senhora Hera voou para longe com urgente pressa; e ela chegou ao íngreme Olimpo ...

O poeta pode mudar de localidade tão rapidamente quanto a deusa. O salto repentino - no espaço e no tempo - é algo que ele consegue não através da experiência real (como o homem bem viajado do símile, ou mesmo Odisseu, quando ele transmite sua narrativa), mas por inspiração divina (como Demódoco). Um traço característico da narrativa homérica vem a ser, assim, uma vez mais, associado com o poder dos deuses.

Parece, então, que o poeta se relaciona com o espaço de uma maneira que revela sua proximidade com as Musas. Em nenhuma outra passagem isso seja talvez mais óbvio do que nos catálogos monumentais do canto II, e na descrição do escudo de Aquiles no canto XVIII. Estas peças inseridas são feitos divinos de visualização, mas de maneira radicalmente diferente: enquanto o Catálogo das Naus e o Catálogo dos Troianos oferecem vistas panorâmicas sobre o mar Egeu oriental e além dele, o escudo de Aquiles oferece uma 
percepção microscópica. Talvez seja mais fácil acompanhar os catálogos do poeta no canto II em um mapa, que forneço (de um modo meio feito-em-casa) para facilitar a referência:

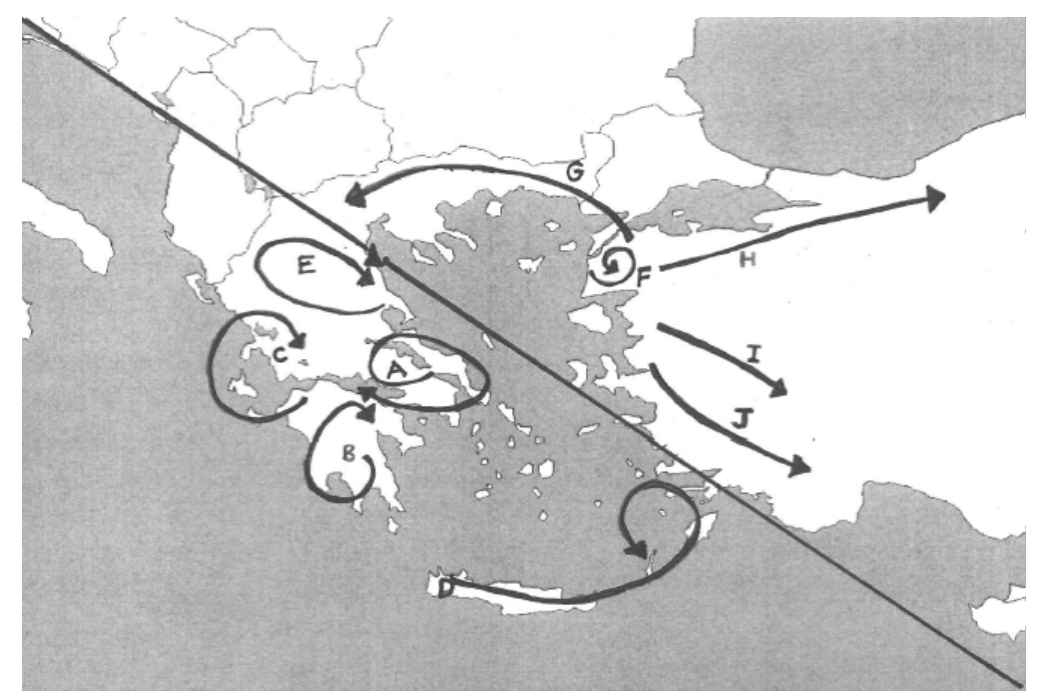

O poeta começa seu Catálogo das Naus em Áulis, onde o contingente aqueu se reuniu, antes de embarcar para Troia. ${ }^{37}$ Ele então se move em uma espiral para oeste, norte, leste e sul (II, 494-580, seta A no mapa). Uma segunda espiral começa na Lacedemônia e se move para o oeste e o norte (II, 581-614, seta B). Uma terceira começa em Élis, e novamente se move para o oeste e depois para o norte, para incluir Ítaca e Cálcis (II, 615-44, seta C). Numa quarta espiral, o poeta menciona Creta, em seguida move-se para o leste e o norte, incluindo Rodes, Cime e Cós (II, 645-80, seta D). O catálogo se conclui no norte da Grécia, a partir da Ftia, movendo-se depois para o norte e o oeste até Dodona, e depois de volta para o leste, até o Pélion (II, 681-759, seta E). Um controle semelhantemente claro e visual da geografia emerge do menos extenso Catálogo dos Troianos: o poeta começa em Troia, em seguida espirala para fora, primeiro para o nordeste, depois novamente para o sul (II, 816-43, seta F). Ele, então, continua na Trácia e se move para o oeste (II, 844-57, seta G). Da Mísia, mais ao sul, ele se move para o leste até a Frígia (II, 858-63, seta H); então, ao listar os Meônios, o poeta se move do oeste para leste (II, 864-6, seta I); finalmente, a partir de Mileto, ele se move para o sudeste até a Lícia (II, 867-77, seta J). Na ausência do GoogleEarth, temos de imaginar como o poeta podia ver o que descreve: sua perspectiva aérea era - devemos concluir - próxima da dos deuses. Adicionando algo à sua análise publicada em 2004, Danek me mostrou, em conversa, que as duas áreas designadas pelo Catálogo das Naus e pelo Catálogo dos Troianos podem ser separadas por uma linha reta - e que o Monte Olimpo está precisamente nessa linha. As Musas "que têm suas casas no Olimpo"

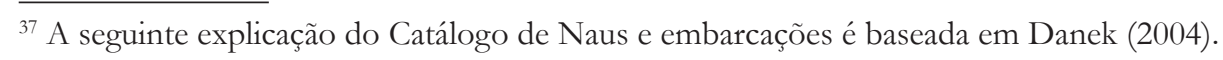


são invocadas no início do Catálogo das Naus (II, 484-93, citado acima: referência cruzada) e os catálogos que se seguem são claramente informados pela perspectiva delas.

Cada seta traça uma viagem de cidade para cidade, e de um lugar para outro; mas o arranjo geral envolve saltos de um lugar, ou melhor, de uma visão para outra: as espirais e os saltos, juntos, ajudam a designar áreas geográficas, em vez de simples itinerários. ${ }^{38}$ Tal como os cientistas cognitivos têm demonstrado, a viagem hodológica de lugar para lugar ao longo de uma rota é como na verdade rememoramos o espaço - e este é um ponto que Minchin destaca eloquentemente. ${ }^{39}$ Mas o que mais me interessa é o salto: o paralelo mais próximo para ele é fornecido por Zeus no início do canto XIII, quando ele olha para a planície de Troia a partir do Monte Ida, e de repente vira seu olhar para mais longe - para os Trácios, os Mísios, os Hipemolgos e os Ábios (XIII, 1-10, citado acima, em referência cruzada). Como Zeus, o poeta também goza de uma vista panorâmica de todo o mundo grego e troiano, e pode mudar o olhar de um lugar para outro. Ele não se limita a rememorar uma viagem linear, como um viajante, mas antes oferece uma visão panorâmica, traçando uma pequena espiral ou linha aqui, e em seguida outra ali. Com a ajuda de um mapa, podemos acompanhar o olhar do poeta, enquanto ele espirala para fora de Áulis e depois salta para baixo, para observar o Peloponeso; ou, ainda, podemos começar em Troia e, em seguida, viajar com nosso olhar afora para o oeste, e, em seguida, de volta para Troia e para o leste, e mais longe para o sudeste. Strauss Clay mostra como o poeta pode visualizar todo o campo de batalha; esta análise dos catálogos do canto II sugere que ele tem todo o mundo conhecido sob controle visual.

A descrição do Escudo de Aquiles oferece um exemplo bastante diferente de como o poeta vê o mundo de uma maneira que requer poderes divinos de visão. A écfrase do canto XVIII atraiu, é claro, uma grande atenção da crítica: tudo o que posso oferecer aqui são algumas breves observações destinadas a coordenar estudos detalhados sobre o Escudo com meu argumento sobre a voz do poeta. Duas características do Escudo parecem especialmente relevantes. A primeira diz respeito ao arranjo das cenas: parece que o escudo apresenta círculos concêntricos, cada um dos quais decorado com (uma) diferente(s) cena(s). Mas quantos círculos existem, e quais as cenas que eles apresentam, permanecem questões em debate. Há muito pouca orientação sobre a transição de uma cena para outra, e por isso é difícil estabelecer quando exatamente o poeta pula fora de um círculo para o próximo. Esta incerteza sobre o arranjo exato das cenas no Escudo é uma versão específica de uma característica mais geral da narrativa homérica, que já discuti: o poeta parece estar sempre ali, presente; saltos acontecem sem muito aviso, porque transições longas e trabalhadas prejudicariam essa sensação de presença. A segunda característica marcante do Escudo é que ele retrata imagens em movimento: estrelas nascem e se põem; pessoas gritam umas para as outras em um processo judicial, e são então pacificadas; há guerras, discussões, emboscadas, estações, danças, casamentos e canções - todos os quais acontecem no decorrer do tempo.

\footnotetext{
${ }^{38}$ Aqui, fico do lado de Danek, 2004, e contra Clay, 2011, p. 117.

${ }^{39}$ Minchin (2001).
} 
Parece como se devêssemos imaginar pequenas tiras de filme projetadas em cada seção circular do Escudo. E há efeitos sonoros também: isso não é cinema mudo, mas sim uma impossível miragem multimídia. Se consideramos o tamanho do escudo, toda a criação se torna ainda mais desconcertante. Por um lado, as dimensões do escudo são determinadas pelo tamanho do corpo de Aquiles - mas, por outro, o escudo deve certamente ser muito maior, de modo a conter todos os detalhes que o poeta descreve. Como aponta Purves, "as imagens retratadas são tão extensas que - a fim de serem vistas pelo olho humano - devem ser reduzidas de uma maneira sobrenatural." ${ }^{40}$ O poeta tem, então, uma visão microscópica, assim como é capaz de ver todo o Mediterrâneo oriental em uma olhada.

Que os mortais comuns não podem realmente suportar o escudo de Aquiles é algo confirmado no próprio texto: Aquiles maravilha-se com a complexidade desta arma e imediatamente a reconhece como trabalho dos deuses (XIX, 21-2); os Mirmidões, pelo contrário, não podem de jeito nenhum olhar para ele - e fogem aterrorizados (XIX, 14-15). Purves conclui com razão: “o Escudo é um símbolo visual importante na Ilíada, porque ele por si só nos permite ver como poderíamos imaginar que os Olímpios veem, isto é, de um ponto de vista divino e elevado, e como as Musas veem - ao longo de um conjunto potencialmente infinito de espaço e de tempo." ${ }^{41}$ Que as audiências antigas ficaram impressionadas e inquietadas pela descrição do escudo no canto XVIII é algo confirmado por uma história preservada para nós na Vita Homeri (Vida de Homero) 6, 45-51:

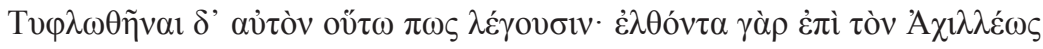

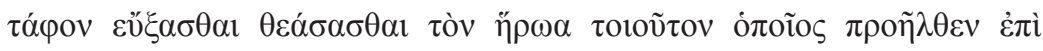

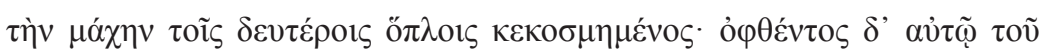

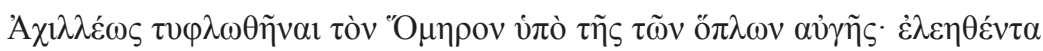

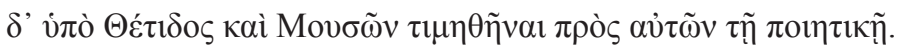

Dizem que Homero ficou cego da seguinte maneira: quando ele veio até o túmulo de Aquiles, suplicou para contemplar o herói como ele apareceu quando partiu para a batalha, adornado com o segundo conjunto de armadura. Mas quando viu Aquiles, Homero foi cegado pelo brilho da armadura. Objeto da compaixão de Tétis e das Musas, ele foi homenageado por elas com o dom da poesia. ${ }^{42}$

Cegueira comum e visão poética vão juntas nesta estória, como em tantas outras narrativas sobre Homero. Específica nesta versão é a estreita ligação entre a voz do poeta como transmitida pelo poema ("o poeta na Ilíada") e antigas ficções biográficas ("o poeta da Iliada"). A passagem ilustra os perigos da presença: Homero suplica para ver Aquiles como ele apareceu aos Mirmidões no início do canto XIX da Ilíada - e (infelizmente para

\footnotetext{
40 Purves, 2010, p. 42.

${ }^{41}$ Purves, 2010, p. 54.

${ }^{42}$ Tradução de Clay, 2011, p. 12, que também oferece uma excelente discussão da passagem.
} 
ele) sua súplica é atendida. Há uma advertência nesta estória: a inspiração poética não sai barato. Talvez nós devamos nos contentar em ouvir a voz do poeta, ao invés de desejar que pudéssemos ver o que ele viu. ${ }^{43}$

[Tradução de Teodoro Rennó Assunção] ${ }^{44}$

\section{REFERÊNCIAS}

BAKHTIN, M. M. The Dialogic Imagination. Translated by C. Emerson and M. Hoquist. Austin: University of Texas Press, 1981.

BAKKER, E. Pointing at the Past: from Formula to Performance in Homeric Poetics. Cambridge: Harvard University Press, 2005.

BÄR, S. Review of Graziosi and Haubold 2010, BMCR 2011.11.29. Disponível em: < http:// bmcr.brynmawr.edu/2011/2011-11-29.html>.

BLOCK, E. The narrator speaks: apostrophe in Homer and Virgil. TAPA, v. 112, p. 7-22, 1982.

BURKERT, W. Greek Religion. Translated by J. Raffan. Cambridge, MA: Harvard University Press, 1985.

CLAY, J. Strauss. Hesiod's Cosmos. Cambridge: Cambridge University Press, 2003.

CLAY, J. Strauss. Homer's Trojan Theater: Space, Vision, and Memory in the Iliad. Cambridge; New York: Cambridge University Press, 2011.

CUILLANDRE, J. La droite et la gauche dans les poèmes homérique en concordance avec la doctrine pythagorienne et avec la tradition celtique. Paris: Les Belles Lettres, 1944.

DANEK, G. Der Schiffskatalog der Ilias: Form und Funktion. In: HEFTNER, H.; TOMASCHITZ, K. (ed.). Ad Fontes! Festschrift für Gerbard Dobesch. Vienna, 2004. p.59-72.

EDWARDS, M. W. The Iliad: A Commentary. Cambridge: Cambridge University Press, 1991. v. 5.

EKROTH, G. The Sacrificial Rituals of Greek Hero-Cults in the Archaic to Classical Periods. Kernos Supplément, Liège: Centre International d’Étude de la Religion Grecque Antique, v. 12, 2002.

\footnotetext{
${ }^{43}$ Eu gostaria de agradecer a Teodoro Rennó Assunção por sua dedicação e competência ao traduzir este artigo, por sua hospitalidade em Belo Horizonte onde apresentei uma versão oral dele, e por sua própria erudição homérica, da qual me beneficiei muito.

${ }^{44} \mathrm{O}$ tradutor agradece, por sua vez, a Tatiana Ribeiro, por sua primeira e cuidadosa revisão, e a Antonio Orlando O. Dourado-Lopes, por sua última e atenta leitura.
} 
FLEISCHMAN, S. Tense and Narrativity: From Medieval Performance to Modern Fiction. Austin: University of Texas Press, 1990.

FORD, A. Homer: The Poetry of the Past. Ithaca: Cornell University Press, 1992.

FRÄNKEL, H. Die Zeitauffassung in der archaischen griechischen Literatur. In: Wege und Formen frühgriechischen Denkens, Munich, 1955, p. 1-22, (First published in Beilagenheft zur Zeitschrift für Ästhetik und allgemeine Kunstwissenschaft 25, 1931, p. 97-118).

GRAZIOSI, B. Inventing Homer: the Early Reception of Epic. Cambridge: Cambridge University Press, 2002.

GRAZIOSI, B; HAUBOLD, J. Homer: The Resonance of Epic. London: Duckworth, 2005.

GRAZIOSI, B; HAUBOLD, J. (ed.). Homer. Iliad, Book VI. Cambridge Greek and Latin Classics. Cambridge; New York: Cambridge University Press, 2010.

GREENWOOD, E. Sounding out Homer: Christopher Logue’s acoustic Homer. Oral Tradition, v. 24, p. 503-518, 2009.

JONG, I. J. F. de. Homer. In: JONG, I. J. F. de; NÜNLIST, R. (ed.). Time in Ancient Greek Literature: Studies in Ancient Greek Narrative. Leiden: Brill, 2007. v. 2, p. 17-37.

JONG, I. J. F. de; NÜNLIST, R. From bird's eye view to close-up: the standpoint of the narrator in the Homeric epics. In: BIERL, A.; SCHMIT'T, A.; WILLI, A. (ed.). Antike Literatur in neuer Deutung. Festschrift für Joachim Latacz anlässlich seines 70. Geburtstages, Munich: De Gruyter, 2004, p. 63-83.

JØRGENSEN, O. Das Auftreten der Götter in den Büchern $1-\mu$ der Odyssee. Hermes, v. 39, p. 357-382, 1904.

MINCHIN, E. Homer and the Resources of Memory: Some Applications of Cognitive Theory to the Iliad and the Odyssey. Oxford: Oxford University Press, 2001.

MIRTO, M. S. Omero: Iliade. Traduzione e saggio introduttivo di Guido Paduano. Commento di Maria Serena Mirto. Turin: Einaudi, 1997.

PORTER, J. I. Making and Unmaking: The Achaean Wall and the Limits of Fictionality in Homeric Criticism. TAPA, v. 141, p. 1-36, 2011.

PURVES, A. Space and Time in Ancient Greek Narrative. Cambridge: Cambridge University Press, 2010.

RICHARDSON, S. D. The Homeric Narrator. Nashville: Vanderbilt University Press, 1990.

ROSSI, A. Contexts of War: Manipulation of Genre in Virgilian Battle Narrative. Ann Arbor: University of Michigan Press, 2004.

SCODEL, R. Zielinski's law reconsidered. Transactions of the American Philological Association, v. 138, p.107-25, 2008. 
TODOROV, T. Mikhail Bakbtin: The Dialogic Principle. Manchester: Manchester University Press, 1984.

WINKLER, M. M. The Iliad and the cinema. In: (ed.). Troy: from Homer's Iliad to Hollywood Epic. Oxford: Blackwell Publishing, 2007, p. 43-67.

YAMAGATA, N. The apostrophe in Homer as part of the oral technique. BICS, v. 36, p. 91-103, 1989.

ZIELINSKI, T. Die Behandlung gleichzeitiger Ereignisse im antiken Epos. Philologus, v. 8, n. 3, p. 407-449, 1901. 